\title{
The challenges of renal replacement therapy and renal palliative care in the elderly
}

\author{
${ }^{1} \mathrm{C}$ Isles, ${ }^{2} \mathrm{~S}$ Robertson, ${ }^{3} \mathrm{~A}$ Almond, ${ }^{4} \mathrm{~K}$ Donaldson, ${ }^{5} \mathrm{D}$ Clark \\ ${ }^{1}$ Consultant Nephrologist, ${ }^{2,3}$ Associate Specialist, ${ }^{4}$ Consultant Nephrologist, Dumfries \& Galloway Royal Infirmary, Dumfries, Scotland; \\ ${ }^{5}$ Professor of Medical Sociology, School of Interdisciplinary Studies, University of Glasgow, Scotland.
}

This review is based on a presentation given by Professor Isles at the joint Royal College of General Practioners and RCPE Medicine for the Elderly Symposium on I April 20II.

\begin{abstract}
The main aim of this review is to let general practitioners and physicians understand what happens to older patients after referral to the renal service. Usually, most patients will be managed completely by the renal team, either because the patient requires dialysis or because conservative but specialised care is appropriate. The recent increase in dialysis rate can mostly be accounted for by older patients for whom such demanding treatment was previously thought to be contraindicated. The decision to dialyse the elderly still remains difficult, with recent data suggesting that if there are significant comorbidities the survival advantage of dialysis in patients over 75 years of age is unlikely to be more than four months. Towards the end of life, conservative treatment is not simply a decision not to dialyse, but comprises active disease management, including treatment of anaemia and other supportive care, which may become increasingly complex, e.g. pain relief with fentanyl and alfentanyl. Older patients who decide to accept dialysis treatment contend with all the usual end of life issues of older people. They have an additional option, denied to the rest of us, of dialysis withdrawal; this effectively allows them to die at a time of their choosing.
\end{abstract}

KEYWORDS Dialysis, older patients, last year of life, palliative care, survival, conservative therapy

DECLARATION OF INTERESTS No conflict of interests declared.

\author{
Correspondence to $C$ Isles, \\ Department of Medicine, \\ Dumfries \& Galloway Royal \\ Infirmary, Bankend Road, \\ Dumfries, DGI 4AP, UK
}

tel. +44 (0) I 387246246 e-mail chris.isles@nhs.net

\section{INTRODUCTION}

Six years ago, El Nahas and colleagues anticipated that 'the worldwide rise in the number of patients with chronic kidney disease (CKD) and consequent end-stage renal disease requiring renal replacement therapy (RRT) threatens to reach epidemic proportions over the next decade.' Fortunately their alarmist view is incorrect, in the UK at least. Most patients with CKD stage 3 do not progress to stages 4 or 5 , which together account for no more than $0.3 \%$ of all patients with chronic kidney disease. $^{2}$ In the UK, the dialysis rate in 1981 was under 27 per million per year ${ }^{3}$, a figure lower than most European countries. Later it seemed that patients were never too old for dialysis and the acceptance rate quadrupled to 123 per million per year in $2005 .{ }^{4}$ For the five consecutive years since then, Scottish Renal Registry data show that the 'take on' rate dropped progressively and in 2010 stood at 97 per million per year ${ }^{5}$ (Figure I). The fall in this rate seems likely to be due to fewer older patients starting dialysis; in $200743 \%$ of all patients were over 65 years of age, compared to $54 \%$ in $2003 .{ }^{4}$
This does not mean that the incidence of established renal failure in the elderly is declining or that the challenge of treating an ever older population has gone away. Prevalence data from the Scottish Renal Registry show that from 2001 to 2010 there was a year on year rise in the total number of patients on RRT. ${ }^{5}$ Since Scottish Government data predict a $70 \%$ increase in the number of people over 75 between 2008 and $2033^{6}$, this increase in RRT is likely to continue. It is against this background that we will review the assessment and management of the elderly with advanced kidney disease. We start with assessment of renal function and treatment options, and then review the latest evidence on survival and quality of life, before closing with observations on the last year of life, dialysis withdrawal and renal palliative care.

\section{ASSESSMENT OF RENAL FUNCTION}

A useful rule of thumb is that every time the creatinine doubles, the glomerular filtration rate (GFR) will halve. ${ }^{7}$ Thus, if a serum creatinine of $62.5 \mu \mathrm{mol} / \mathrm{l}$ and a GFR of $100 \mathrm{ml} / \mathrm{min}$ is our starting point, this means that when 


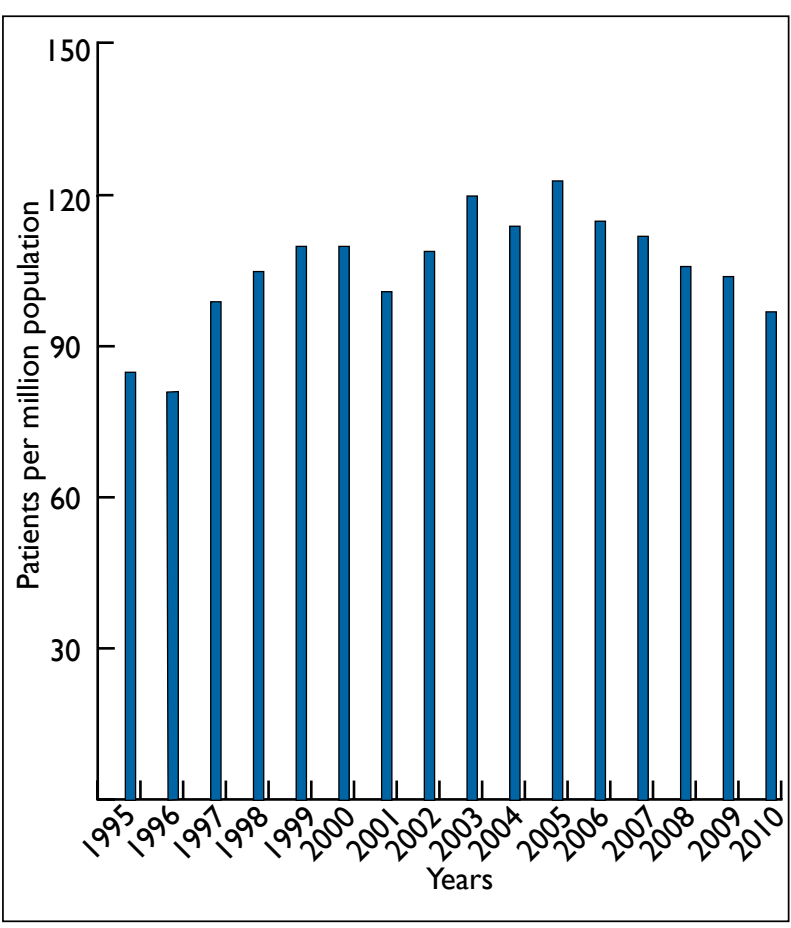

FIGURE I Incidence of renal replacement therapy per million population. Scottish Renal Registry, 1995-2010.

the serum creatinine exceeds $500 \mu \mathrm{mol} / \mathrm{l}$, the GFR will have fallen below $12.5 \mathrm{ml} / \mathrm{min}$. No one mourns the demise of 24 hour urine collections as the basis for calculating creatinine clearance; not only was the collection messy and cumbersome but the results obtained were frequently inaccurate and misleading. The standard method for estimating GFR now is based on the MDRD equation derived in the study on modification of diet in renal disease which estimates GFR on the basis of a patient's age, serum creatinine, gender and race $^{2}$. So, an 82-year-old white female with serum creatinine of $300 \mu \mathrm{mol} / /$ has an estimated glomerular filtration rate (eGFR) of $14 \mathrm{ml} / \mathrm{min}$ (confidence interval [Cl] from 10 to $18 \mathrm{ml} / \mathrm{min}$ ). All biochemistry departments in Scotland now use this formula to report eGFR, but they do not routinely give confidence intervals. The main weakness of the MDRD formula is that it takes no account of muscle mass, which influences the amount of creatinine generated. For patients at extremes of body weight, creatinine clearance is best estimated by the Cockcroft Gault formula (which takes body weight into account). ${ }^{2}$ The take-home message for general physicians and geriatricians is that the underweight elderly female with serum creatinine $300 \mu \mathrm{mol} / \mathrm{l}$ may well have end-stage renal failure.

\section{TREATMENT OPTIONS}

In theory, all patients with established renal failure have the option of hospital haemodialysis, home haemodialysis, peritoneal dialysis (PD), transplantation or conservative care. In practice, no Scottish patients over the age of 80 years are currently being treated by home haemodialysis. There is no theoretical reason why an elderly renal patient should not have a pre-emptive transplant, though this also does not happen. If a trial of RRT is chosen, this effectively means a choice between hospital-based haemodialysis and peritoneal dialysis at home. Studies suggest that with appropriate multidisciplinary support, over $50 \%$ of an elderly population eligible for PD will choose this form of treatment. ${ }^{8}$ However, the uptake is much lower. 9 A UK Renal Registry analysis of patients under 65 years of age on 31 December 2008 showed that a third were treated by haemodialysis, $59 \%$ had a functioning transplant and $8 \%$ were undergoing PD. In the over 65 s the proportion with a functioning transplant was $22 \%$, with an increased proportion of hospital haemodialysis rather than PD (Figure 2). ${ }^{10}$

It is likely that in the elderly, physical problems, social circumstances and cognitive impairment conspire to make PD less attractive. This is ironic given that in a recent UK study, scores estimating the intrusion of therapy and quality of life were found to be better in PD patients than in those who received haemodialysis. II Some Scottish units may promote PD more than others, as judged by the 2.5 -fold variation in uptake reported by the Scottish Renal Registry in 2008 (Figure 3). ${ }^{4}$ A recent development has been assisted Automated PD (aAPD) ${ }^{12,13}$, which allows the patient to be treated at night, with a portable machine that pumps fluid in and out of their peritoneal cavity automatically. With aAPD, a fully trained healthcare assistant visits daily - emptying drainage bags, checking drained fluid for cloudiness, setting up the machine for the next treatment, inspecting the catheter exit site and reviewing stocks of treatment fluids and drugs. These assistants maintain contact with the parent unit which intervenes if problems arise. Latest data suggest a near linear increase in aAPD, used for 135 UK patients by January 2011.14

\section{SURVIVAL}

Some years ago we compared survival of all Scottish patients over 80 years of age who were dialysed between 1994 and 200I, with age-matched myocardial infarction (MI) and lung cancer controls, using data supplied by the Information Services Division of the Scottish Health Service. 15 There were 2I 3 CKD, I 4,398 $\mathrm{MI}$ and 4,655 lung cancer patients in this analysis. Median survival in days, from 90 days after the start of RRT, hospital admission for MI, or cancer diagnosis was 459 days RRT patients), I,242 days (MI patients) and I4I days (patients with lung cancer). Thus octogenarians who are dialysed can anticipate, on average, almost one and a half years on dialysis. Similar survival was reported by the North Thames Study in 200I, which also showed that only age over 80 years and the presence of peripheral vascular disease could predict outcome at 12 months. ${ }^{16}$ 


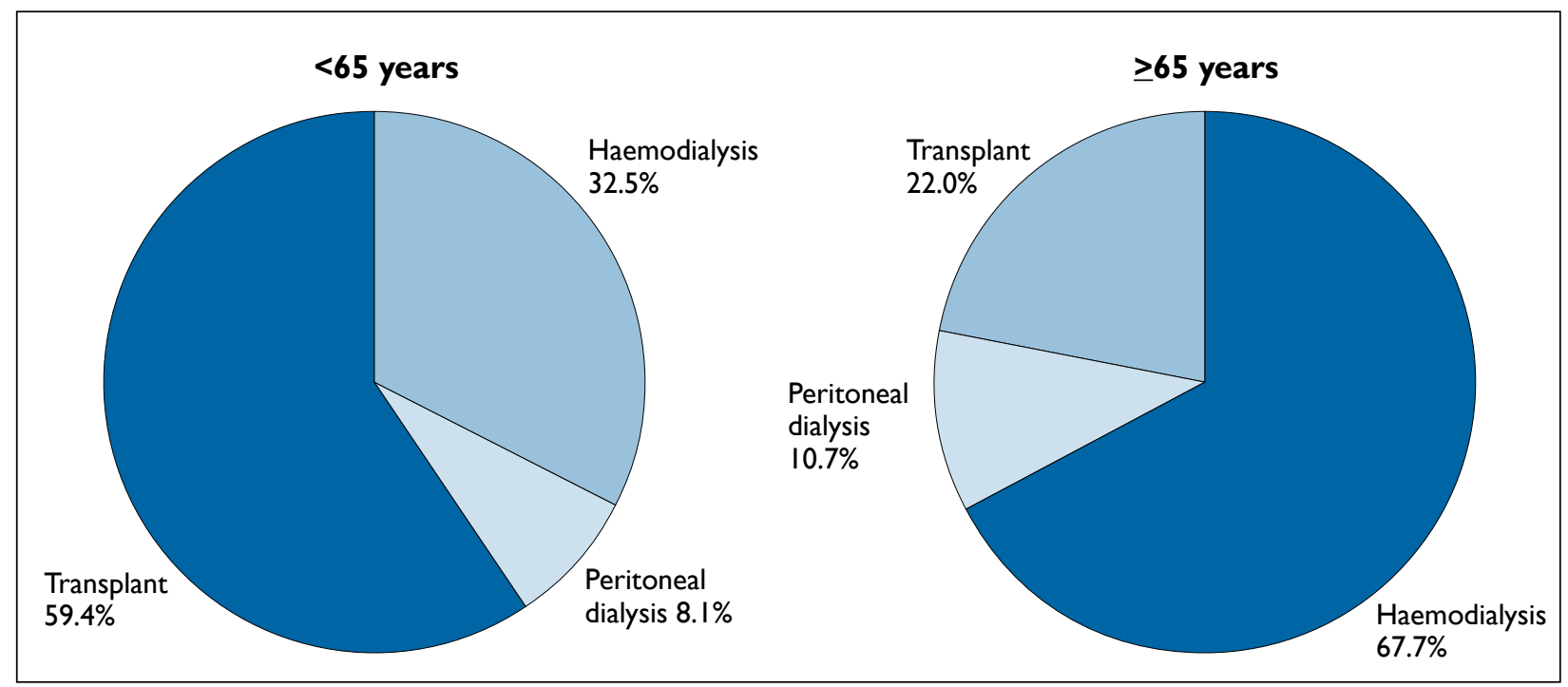

FIGURE 2 UK Renal Registry data showing treatment modality for patients under and over 65 years on 3I December 2008.

A recent report from the Lister Unit in Stevenage revisited the survival of elderly CKD patients in a nonrandomised study. ${ }^{17}$ Eighty-two per cent (689/844) were treated by RRT while $18 \%$ (I55) received conservative management. In these patients, comorbidities (cardiac, peripheral vascular, cerebrovascular, diabetes, respiratory, cancer and cirrhosis) were assigned severity scores from I to 4. Survival was calculated from the first recorded eGFR of less than $15 \mathrm{ml} / \mathrm{min}$, not from the onset of dialysis. At first glance it appeared as if patients treated by RRT (median survival six years) did much better than those who received conservative care (median survival 2.5 years) but when subjects aged over 75 years were analysed separately, with survival adjusted for age, gender, ethnicity, and the presence of diabetes or other

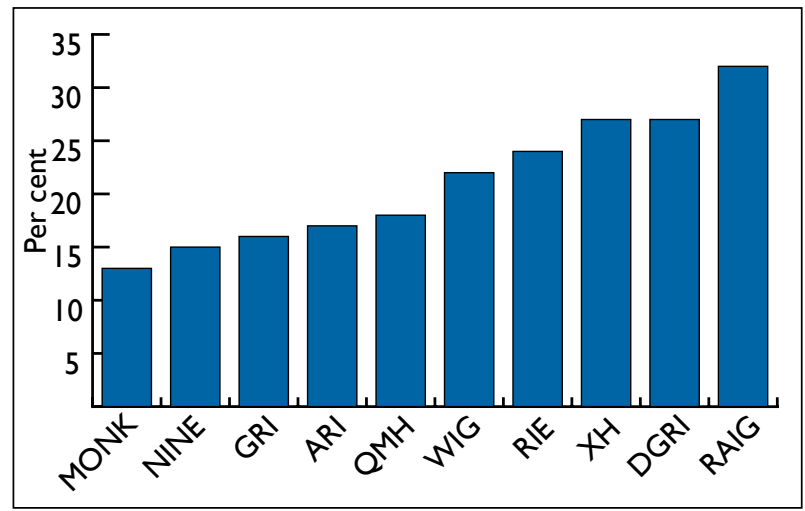

FIGURE 3 Per cent of renal patients on home therapies (excluding transplant) by Scottish Renal Units on 13 December 2007. Monk $=$ Monklands; Nine $=$ Ninewells; GRI $=$ Glasgow Royal;ARI = Aberdeen Royal; QMH = Queen Margaret Hospital, Dunfermline; WIG = Western Infirmary, Glasgow; RIE = Royal Infirmary, Edinburgh; $\mathrm{XH}=$ Crosshouse; Kilmarnock, DGRI = Dumfries \& Galloway Royal Infirmary; Raig = Raigmore, Inverness. high comorbidities, the median survival advantage associated with dialysis fell to four months in the group with comorbidities. The take-home message was that patients over 75 years of age who received RRT achieved a worthwhile survival advantage if there was low comorbidity but that median survival if there was high comorbidity was poor.

\section{QUALITY OF LIFE}

If the survival advantage of dialysis is not as great as hoped for, what kind of quality of life can an elderly patient on dialysis expect? We would anticipate that they would be susceptible to most of the so-called 'geriatric giants': infection, immobility, instability, incontinence and intellectual impairment. In CKD stage 5, infection is an ever-present increased risk, particularly with tunnelled lines, while immobility is common, demonstrated by the number of patients who attend dialysis in wheelchairs. Instability leads to falls and these are greatly increased in CKD. ${ }^{18}$ Urinary incontinence may be a lesser problem than in the general population since many dialysis patients pass little or no urine. Impaired intellect occurs in $13 \%$ of patients with an eGFR of less than $30 \mathrm{ml} / \mathrm{min}$; when it occurs it adds to the burden of a very demanding form of treatment. ${ }^{19}$

Quality of life was measured in the North Thames Dialysis study using Short Form 36 (SF36) scoring. ${ }^{16}$ Physical quality of life was significantly lower in the elderly RRT patients than in UK/US age-matched populations. In contrast, the emotional quality of life of the elderly RRT patients was as good as that of their peers in the general population. ${ }^{16} \mathrm{~A}$ recent US study reported a marked decline of functional status among nursing home residents after initiation of dialysis for end-stage renal disease. ${ }^{20}$ Another US study followed the 
progress of all patients 80 years or older who started dialysis between 2000 and 2005. ${ }^{21}$ At the start of RRT, $78 \%$ were living independently at home, 15\% were living at home with assistance and $6 \%$ were already in nursing homes. After two years of follow-up only II\% of the original cohort ( $18 \%$ of those still alive) were still living independently at home. The remainder required community or private care support or had been transferred to a nursing home. ${ }^{21}$

\section{THE LAST YEAR OF LIFE}

Living and Dying Well, a National Action Plan for Palliative and End of Life Care in Scotland, gives clinical prognostic indicators for each of the major organ failures that might suggest a patient was entering their last year of life. ${ }^{22}$ For CKD the clinical prognostic indicators of the final year of life are: I) CKD stage 5 patients not seeking RRT or discontinuing such treatment, from choice, due to frailty or too many comorbid conditions and 2) CKD stage 5 patients whose condition is deteriorating and who are likely to die in the next year. The Living and Dying Well document also states that comorbidity is the best predictor of mortality, giving as measures: weight loss $>10 \%$ in the last six months; general physical decline; serum albumin $<25 \mathrm{~g} / \mathrm{l}$; and dependence on others for most activities of daily living. ${ }^{22}$

A Scottish survey of all patients in an acute hospital on 31 March 2008 showed that 4,450/|4,868 (3I\%) had died by 3 I March 2009. The proportion dying within that year rose to $38 \%$ when the analysis was limited to patients aged 65 years and over. When deaths in the over $65 \mathrm{~s}$ were analysed by specialty it was found that deaths in renal medicine $(50 \%)$ exceeded those of general medicine (4I\%) and of geriatric medicine $(40 \%){ }^{23}$ In an analysis of emergency medical admissions in Dumfries, 59/145 (41\%) of patients who were in hospital on I September 2009 had died within one year, only five $(8 \%)$ of these having died at home (Figure 4$)$. A recent study from Ireland shows the inexorable increase in the proportion of deaths occurring in hospitals or institutions from I 885 (I5\%) to 2005 (75\%). ${ }^{24}$ Together, these data suggest that we should begin to re-orientate our medical practice to meet the palliative and supportive care needs of elderly patients with end-stage renal disease, more fully, when they are admitted to hospital.

\section{DIALYSIS WITHDRAWAL}

Dialysis withdrawal is probably the most common cause of death for patients on RRT. In a French study, 196 of I,436 dialysis patients died during follow-up. ${ }^{25}$ The single most common cause of death was dialysis withdrawal (defined as death occurring more than three days since the last dialysis), which accounted for no fewer than $20 \%$ of all deaths. Mean survival time after the last treatment session was 8.5 days (median seven days). Survival is

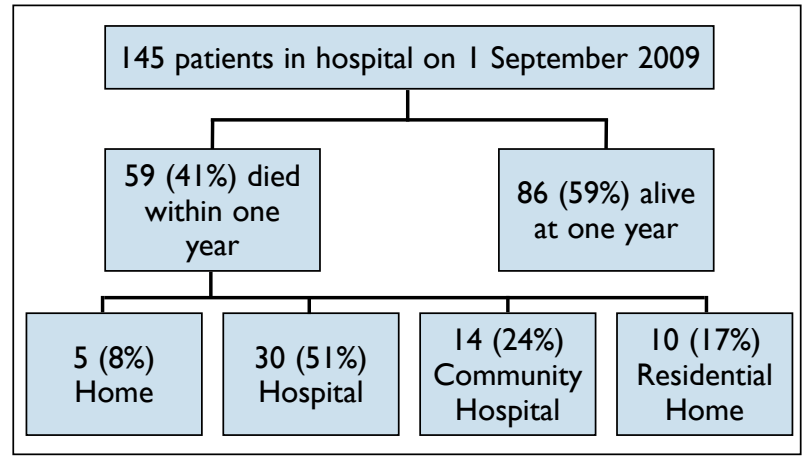

FIGURE 4 Emergency admissions to medicine in Dumfries on I September 2009.

likely to be longer in patients with residual renal function. Advanced care planning may not have been common in the units investigated because 32 of the 40 patients in whom dialysis was withdrawn were reported as being too weak or ill to participate in the decision.

Discussion of dialysis withdrawal can be a very sensitive issue if it is seen as the withholding of a life-saving treatment in an elderly patient. When Professor $\mathrm{P}$ Hanlon observed in a recent Newsnight interview that death was part of the cycle of life and that it might not always be appropriate to treat older people in their last year intensively ${ }^{26}$, he received some very negative press. However, many elderly dialysis patients perceive their quality of life to be much better than we might surmise. Nephrologists need to accept that, though it may not be what we would wish for ourselves, some patients may be very content to sit surrounded by their family. There also needs to be debate about whether the National Health Service (NHS) can afford such an expensive and demanding treatment for people with restrictions on their day to day lives.

\section{RENAL PALLIATIVE CARE}

For elderly dialysis patients, renal palliative care should begin at the time of diagnosis and continue throughout the rest of the patient's life. The elements of such disease care include symptom control, psychosocial and spiritual support, in addition to consideration of the particular ethical issues of dialysis. ${ }^{27}$ The National Service Framework for Renal Services states that people with established renal failure should receive 'timely evaluation of their prognosis, information about the choices available to them, and for those near the end of life, a jointly agreed palliative care plan, built around their individual needs and preferences'. ${ }^{28}$ Good renal palliative care should include advanced care planning even if most renal patients appear reluctant to consider this option. Renal palliative care then continues with attention to symptoms that are often under-recognised. A systematic review of 60 studies in 2006 showed the following values for weighted mean symptom prevalence in end-stage 
renal disease: fatigue/tiredness (7l\%), pruritis (55\%), constipation $(53 \%)$, anorexia (49\%), pain $(47 \%)$, sleep disturbance (44\%), anxiety (38\%), dyspnoea (35\%), nausea $(33 \%)$, restless legs $(30 \%)$, and depression (27\%). ${ }^{29}$ Multiple symptoms were common in patients on dialysis.

Treatment of symptomatic anaemia with erythropoiesis stimulating agents and intravenous iron, one of the renal success stories of the last decade, can reduce the need for blood transfusions..$^{30}$ Evidence from the Liverpool Care Pathway study suggests that pain is also a frequent symptom in patients with end-stage CKD and that pain control is often challenging. ${ }^{31}$ In renal failure, active metabolites of morphine accumulate and cause severe symptoms (myoclonic jerks, profound narcosis and respiratory depression), so before relieving pain we should use those opiates that do not accumulate in renal disease such as fentanyl or alfentanyl. ${ }^{32}$ Fentanyl can be given by patch, subcutaneously or intravenously, and in practice a fentanyl patch, with oxycodone orally at home, or alfentanyl subcutaneously in hospital, is usually effective. Patients whose pain is not controlled despite such opioids should be referred to the palliative care team if this has not been done already.

The trajectory for organ system failure is shown in Figure $5 .^{33} \mathrm{~A}$ gradual decline in function punctuated by hospital admissions which become more frequent towards the end of life is common in renal failure. Death often seems 'sudden' to many relatives of renal patients even if the gradual and progressive decline in that patient's health has been obvious to the hospital team. Most patients whose dialysis is withdrawn die after becoming progressively more drowsy and slipping into uraemic coma. If death occurs suddenly, asystole due to hyperkalaemia is the likely trigger. Nausea and dyspnoea can be controlled relatively easily by haloperidol, fentanyl or alfentanyl in a syringe driver, although pain control may remain problematic. One US study showed that only $15 \%$ of patients had 'bad deaths' following the decision to terminate dialysis; the study highlighted the complexity of decisions to cease treatment and the importance of excellent palliative care. ${ }^{34}$ Many renal units now have renal palliative care nurse specialists who are skilled in uraemic symptom control and whose remit also includes support for the family and carers, both before and after death. ${ }^{35}$

\section{CONCLUSIONS}

I. Elderly patients with a serum creatinine of $>300$ $\mu \mathrm{mol} / \mathrm{l}$ may well have end-stage renal disease, especially if they are female and underweight.

2. Age is not a contraindication to dialysis in the elderly but significant comorbidities may be.

3. Peritoneal dialysis is under-utilised in the elderly, but assisted PD may mean that more elderly people can be treated in this way.

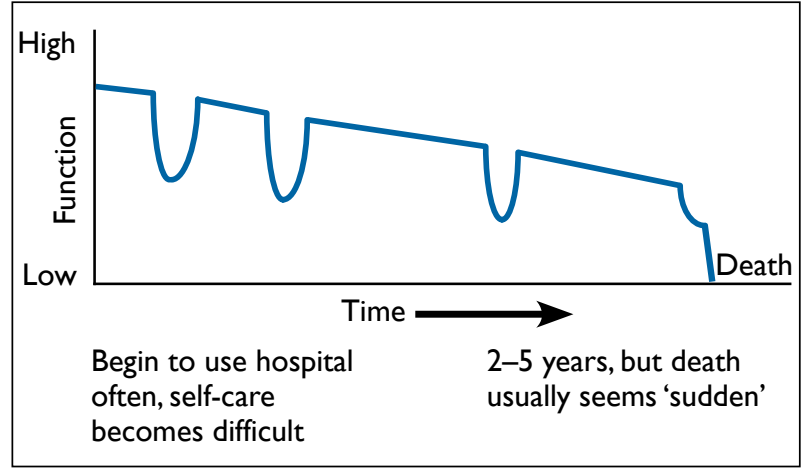

FIGURE 5 Organ system failure trajectory.

4. Dialysis in patients over 80 years of age may prolong life by only a few months, if significant comorbidities are present.

5. Emotional quality of life on RRT appears to be as good as that of patients of similar age who do not have CKD.

6. Renal patients have an option denied to the rest of us of dialysis withdrawal, which effectively allows them to die at a time of their choosing.

7. Dialysis withdrawal is now the most common cause of death for patients on RRT.

8. Renal palliative care for elderly dialysis patients should begin at the time of diagnosis and continue throughout life. It differs from non-renal palliative care in many respects, not least of which are the efficacy of erythropoiesis stimulating agents and intravenous iron for renal anaemia and the use of fentanyl and alfentanyl for pain control.

9. A 'good renal death' is possible but only if good palliative care is available.

While these challenges mainly concern the nephrologist who manages chronic renal disease in the elderly, we feel that many will also be of interest to other physicians. 


\section{REFERENCES}

I El Nahas MA, Bello AK. Chronic kidney disease: the global challenge. Lancet 2005: 365;33|-40. doi:/10.1016/50I40-6736(05) I7789-7

2 Levey AS, Coresh J, Balk E et al. National Kidney Foundation practice guidelines for chronic kidney disease: evaluation, classification and stratification. Ann Intern Med 2003; 139:137-47.

3 Challah S, Wing AJ, Bauer R et al. Negative selection of patients for dialysis and transplantation in the United Kingdom. Br Med J 1984; 288: I I 19-22. doi:I0.1 I36/bmj.288.6424.III9

4 NHS Scotland. Scottish Renal Registry Reports 2008/2009. [Internet] Scotland: NHS National Services; 2009.Available from: http://www. srr.scot.nhs.uk/Publications/scottish-renal-registry-report-2008web.pdf and http://www.srr.scot.nhs.uk/Publications/Downloads/ SRR2009_SectionB_Prevalence.pdf

5 NHS Scotland. Scottish Renal Registry Provisional Report 2010 [Internet]. Scotland: NHS National Services; 20I I. Available from http://www.srr.scot.nhs.uk/About/PDF/Incidence_\&_Prevalence_ Report_2010_Inverness_250320II.pdf

6 General Register Office for Scotland. Projected population of Scotland (2008 based). [Internet]. Scotland: GRO Scotland; 2009. Available from: http://www.gro-scotland.gov.uk/files2/stats/ projected-population-of-scotland-2008-based/

7 Anderson RJ. Clinical and laboratory evaluation. In: Jorres A, Ronco C, Kellum JA, editors. Management of acute kidney problems. Heidelberg: Springer; 2010. p.83-91. doi:10.1007/978-3-5406944I-0_9

8 Oliver MJ, Quinn RR, Richardson EP et al. Home care assistance and the utilisation of peritoneal dialysis. Kidney Int 2007; 7I:673-78. doi:I0.1038/sj.ki.5002107

9 Tesar V. Peritoneal dialysis in the elderly - is its underutilisation justified? Nephrol Dial Transplant 2010; 25:3473-76. doi:I0.1093/ ndt/gfq562

10 UK Renal Registry 2009.

II Brown EA, Johansson L, Farrington $\mathrm{K}$ et al. Broadening Options for Long term Dialysis for the Elderly (BOLDE): differences in quality of life on peritoneal dialysis compared to haemodialysis for older patients. Nephrol Dial Transplant 2010:25:3755-63. doi: I0.1093/ndt/ gfq2I2

12 Dimkovic N, Oreopoulos DG.Assisted peritoneal dialysis as a method of choice for elderly with end stage renal disease. Int Urol Nephrol 2008; 40: I 143-50. doi:I0.1007/s I 1255-008-9427-7

13 Povlsen JV, Ivarsen P. Assisted peritoneal dialysis: also for the late referred elderly patient. Perit Dial Int 2008; 28:46I-67.

14 Data on file. Baxter Healthcare 2011.

15 Ronsberg F, Isles C, Simpson $\mathrm{K}$ et al. Renal replacement therapy in the over 80s. Age Ageing 2005; 34:148-52. doi:10.1093/ageing/ afiO24

16 Lamping DL, Constantinovici N, Roderick P et al. Clinical outcomes, quality of life and costs in the North Thames Dialysis Study of elderly people on dialysis: a prospective cohort study. Lancet 2000; 356:154350. doi: $10.1016 / 50140-6736(00) 03123-8$

17 Chandna SM, Da Silva-Gane M, Marshall C et al. Survival of elderly patients with stage 5 CKD: comparison of conservative management and renal replacement therapy. Nephrol Dial Transplant 201 I; 26:1608-14. doi:10.1093/ndt/gfq630

18 Cook WL, Tomlinson G, Donaldson, $M$ et al. Falls and fall related injuries in older dialysis patients. Clin J Am Soc Nephrol 2006; I:I 197-I 204. doi:I0.22I5/CJN.0I650506

19 Tamura MK, Xie D, Yaffe K et al.Vascular risk factors and cognitive impairment in chronic kidney disease: the Chronic Renal Insufficiency Cohort (CRIC) Study. Clin J Am Soc Nephrol 20II; 6:248-56. doi:I0.2215/CJN.026603I0

20 Tamura MK, Covinsky KE, Chertow GM et al. Functional status of elderly adults before and after initiation of dialysis. N Engl J Med 2009; 361:1539-47. doi:I0.1056/NEJMoa0904655

21 Jassal SV, Chiu E, Hladunewich M. Loss of independence in patients starting dialysis at 80 years of age or older. N Engl J Med 2009. 361:16|2-13. doi:10.1056/NEJMc0905289
22 The Scottish Government. Living and Dying Well. A national action plan for palliative and end of life care in Scotland [Internet]. Scotland: Scottish Government; 2008. Available from: http://www.scotland. gov.uk/publications/2008/10/01091608/0

23 Information Services Division, National Services Scotland. Scottish survey of deaths at one year. Scotland Audit of death rates in acute hospitals 2008-9. Information Services Division: Scotland.

24 McKeown K, Haase T, Pratschke J et al. Dying in hospital in Ireland: an assessment of the quality of life in the last week of life. National Audit of end of life care in hospitals in Ireland, 2008/9. Report 5, Final Synthesis Report. Dublin: Irish Hospice Foundation; 2010.Available from: http://epubs.rcsi.ie/icubhrep/l//

25 Birmele B, Francois M, Pengloan J et al. Death after withdrawal from dialysis: the most common cause of death in a French dialysis population. Nephrol Dial Transplant 2004; 19:686-91. doi:|0.1093| ndt/gfg606

26 Hanlon P. Call to reform elderly healthcare. Newsnight Scotland 10 January 2011.

27 Holley JL. Palliative care in end stage renal disease: focus on advanced care planning, hospice referral and bereavement. Semin Dial 2005; 18:154-56. doi:10.1III/j.1525-I39X.2005.18208.x

28 Department of Health. The National Service Framework for Renal Services Part 2: chronic kidney disease, acute renal failure and end of life care [Internet]. Department of Health; February 2005. Available from: http://www.dh.gov.uk/en/PublicationsandStatistics/Publications/ Publicationspolicyandguidance/DH_4I0I902

29 Murtagh F,Addington-Hall J, Higginson IJ.The prevalence of symptoms in end stage renal disease: a systematic review. Adv Chronic Kidney Dis 2007; 14:82-99. doi:I0.1053/j.ackd.2006.10.001

30 The National Institute for Health and Clinical Excellence (NICE). Anaemia management in people with chronic kidney disease: full guidance [Internet] NICE; 20II. Available from: http://guidance. nice.org.uk/CGI I4/Guidance/pdf/English.

3I DH Renal NSF Team and Marie Curie Palliative Care Institute. Liverpool Care Pathway for the dying patient: guidelines for Liverpool Care Pathway drug prescribing in advanced chronic kidney disease. June 2008. Available from: http://www.dh.gov.uk/en/Publicationsandstatistics/ Publications/PublicationsPolicyAndGuidance/DH_085320

32 Conway BR, Fogarty DG, Nelson WE et al. Opiate toxicity in patients with renal failure. BMJ 2006; 332:345-46. doi:|0.1136/ bmj.332.7537.345

33 Murray SA, Kendall M, Boyd $\mathrm{K}$ et al. Illness trajectories and palliative care. BMJ 2005; 330:1007-II. doi:|0.11361 bmj.330.7498.1007

34 Cohen LM, Poppel DM, Cohn GM et al. A very good death: measuring quality of dying in end stage renal disease.J Palliat Med 200I; 4:167-72. doi:I0.1089/109662I01750290209

35 Harrison K, Watson S. Palliative care in advanced kidney disease: a nurse-led joint renal and specialist palliative care clinic. Int J Palliat Nurs 201 I; 17:42-46. 